\title{
Pueblos indígenas y Estado costarricense: disputa de derechos y control territorial
}

Recibido: 23 de abril 2018

Revisado: 13 de junio 2018

Aprobado: 12 de setiembre 2018

Juan Antonio Gutiérrez Slon

Costarricense. Sociólogo

graduado por la Universidad Nacional de Costa Rica (UNA) y

Master en Historia por la

Universidad de Costa Rica

(UCR). Con estudios en

movimientos, política y culturas

indígenas. Cuenta con

experiencia en docencia e investigaciones interculturales.

Estudioso de temáticas

juveniles y participación en acciones ecologistas. Trabaja en el Centro de Investigaciones en Cultura y Desarrollo (CICDE) de la Universidad Estatal a Distancia (UNED). Correo electrónico: jgutierrez@uned.ac.cr

César Moya Aburto Costarricense. Licenciado en Antropología por la Universidad de Costa Rica. Dentro de sus

intereses investigativos se encuentran los relacionados con pueblos indígenas, sus luchas políticas y la autonomía. Cuenta con experiencia en investigaciones sobre aspectos simbólicos y culturales de pueblos indígenas. Trabaja en el Centro de Investigación en Cultura y Desarrollo (CICDE) de la Universidad Estatal a

Distancia (UNED). Correo electrónico: cmoya@uned.ac.cr
Resumen: Este artículo busca poner en perspectiva las demandas de pueblos indígenas frente al Estado costarricense, principalmente desde sus luchas por el territorio y autonomía en un contexto de más de cuarenta años de demanda de derechos. Se discute desde las mismas resistencias, denuncias, demandas y propuestas de pueblos indígenas en una relación plasmada por la disputa con la institucionalidad del Estado en momentos en que este pareciera no atender la agenda planteada por los territorios indígenas del país.

Palabras clave: Territorio; pueblos indígenas; estado; ley; autonomía; movimiento indígena

\section{Indigenous Peoples and the Costa Rican State: Dispute over Rights and Territorial Control}

Abstract: This article seeks to put in perspective the demands of indigenous peoples against the Costa Rican State, mainly from their struggles for territory and autonomy in a context of more than forty years of demand for rights. It is discussed from the same resistance, denunciations, demands and proposals of indigenous peoples in a relationship shaped by the dispute with the institutionality of the State at a time when it seems not to address the agenda set by the indigenous territories of the country.

Key words: Territory; indigenous peoples; state; law, autonomy; indigenous movement 


\section{Introducción}

Este artículo es una reflexión sobre las demandas que organizaciones y dirigencia de los ocho pueblos indígenas costarricenses han planteado en el contexto de sus relaciones políticas con el Estado, en un escenario de pasado reciente. El artículo surge como motivación para comprender una secuencia que antecedió a los actuales procesos de lucha por la recuperación de tierras que varios pueblos y territorios indígenas de la Zona Sur del país han realizado desde el año 2010.

Las reflexiones incluyen un recuento enmarcado en el contexto de luchas, movilizaciones y demandas que diferentes pueblos originarios han venido planteando en aspectos sociales, culturales, económicos y políticos, los cuales aseguran que les afectan en la consagración plena de sus derechos como pueblos, optando por procesos de organización en consecutivas muestras de lucha social desde la década de 1970, impactando la realidad de los territorios indígenas, tanto del Caribe como de la Zona Sur costarricenses.

Este conjunto de acciones de protesta, denuncia, demanda y propuestas, ha ido configurando una agenda política indígena centrada en consignas ligadas al derecho colectivo de estos pueblos que se traduce en luchas de defensa de la tierra, autonomía, no intromisión territorial y el reconocimiento de autoridades tradicionales.De esta manera, el artículo se divide en cinco apartados: el primero, Desposesión histórica de tierras indígenas, expone una breve contextualización histórica desde la Colonia hasta el siglo actual, para mostrar que la relación colonial del Estado, instituciones estatales y extranjeras aún persiste; a esto se le suman las amenazas de megaproyectos hidroeléctricos, mineros y productivos, así como el aumento en la usurpación de territorios indígenas, temas que se profundizarán en el tercer apartado.

El segundo, Vestigios del territorio indígena, muestra la creación de varios territorios indígenas como zonas exclusivas para los pueblos indígenas, delimitados para su uso desde principios de siglo XX, esto, sin embargo, no consolidó otros derechos como el de participación indígena en las decisiones que les atañen ni el respeto fidedigno de estos territorios. En ese contexto de relaciones colonialistas, el tercer apartado, Luchas y demandas de pueblos indígenas, muestra cómo los pueblos indígenas se han organizado frente a problemáticas de educación, defensa de sus territorios, oposición a la extracción minera y en la exigencia de derechos como pueblos y territorios indígenas frente al Estado. Esta misma organización desde los indígenas, como se indica en la cuarta sección sobre el Proyecto de Ley de Desarrollo Autónomo, se discute como una propuesta para controlar sus territorios desde el autogobierno, además, se detallan algunos momentos claves del proyecto en 
la corriente legislativa y las posiciones a favor y en contra que manifestaron las organizaciones indígenas y actores cercanos a la materia.

Desligándose de este punto, en el quinto apartado, Desalojo violento y la lucha desde los territorios, se discute la propuesta indígena de hacer efectiva la autonomía territorial desde las mismas comunidades indígenas, emprendiendo luchas de recuperación de tierras en los últimos ocho años. Finalmente, se cierra con unas reflexiones finales acerca de la centralidad del territorio en la autonomía de los pueblos originarios y la vigencia de sus luchas aún en contextos de mayor liberalización económica del país.

\section{Desposesión histórica de tierras indígenas}

Los pueblos indígenas han estado inmersos en una disputa por el territorio, por la defensa de los recursos que se encuentran en sus tierras y de sus particularidades culturales desde el momento mismo de la Conquista y Colonización. De esta manera, el desplazamiento forzado de sus tierras ha sido un proceso continuo desde el siglo XV y presente aún en el siglo XXI (Chacón y Guevara 1992).

Desde la colonización europea en las tierras habitadas por los pueblos originarios en América, se ha ejercido una arrebatada constante de sus formas de vida, saqueos de riquezas e imposición de estructuras de explotación indígena; obligándoles a realizar trabajos forzados y ser repartidos mediante sistemas como la encomienda, reducción, mita, esclavitud y desplazamientos forzados para hacer posesión de las tierras que residían (Chacón y Guevara, 1992).

En el caso de los pueblos indígenas que han habitado el territorio que hoy se designa como Costa Rica, estas acciones de sometimiento y desplazamiento también se replicaron durante los siglos XVI, XVII y XVIII de Colonización, se replicaron acciones de dominio y explotación, con gran cantidad de indígenas desplazados, muertos o aculturalizados, deviniendo a menos en sus formas de vida y pervivencia como pueblos, como en el caso de los indígenas huetar, originalmente ubicados en la región central del país, y en la zona de Guanacaste donde habita el pueblo Chorotega, se dieron desplazamientos y muerte física y cultural; hasta el punto de que en algunos casos se llegó hasta el exterminio, tal cual sucedió con los pueblos cotos y quepos, que habitaron la zona sur del país (Chacón y Guevara 1992, 17).

En el caso del pueblo brunka -también de la Zona Sur del país- que pervive en la actualidad, sus tierras fueron punto de interés de la Colonia debido a que esta región ofrecía una zona de menor dificultad de acceso y con mejores condiciones climáticas, por lo que sirvió de punto estratégico para los CoIonizadores y la Corona Española para la movilización e intercambio comercial (Chacón y Guevara 1992, 33). 
Por el contrario, la zona Atlántica de Talamanca -donde actualmente habitan los pueblos bribri y cabécar- nunca fue dominada por los españoles debido a las difíciles condiciones geográficas y climáticas (Chacón y Guevara 1992, 18-19), además de la resistencia que siempre mostraron los diferentes pueblos indígenas talamanqueños, entre las que sobresale la resistencia de $\mathrm{Pa}$ brü Presberë en 1709 (Barrantes 1985).

Esta situación de desplazamiento, ocupación de sus tierras, muerte de sus habitantes, transculturación forzada de las y los sobrevivientes y sometimiento fue la tónica durante los siglos ya mencionados, por lo que, al arribo de los procesos independentistas vividos en las primeras décadas del siglo XIX (en todo el continente latino y en la región de América Central), las poblaciones indígenas seguían manteniendo una condición subalterna, de sumisión y sometimiento que las nacientes repúblicas heredaron del período Colonial (Ibarra 1982, 182).

De esta manera, con el inicio del período independiente de Costa Rica en 1821, la marginalidad indígena y el despojo, así como los desplazamientos desde sus tierras, seguía siendo la forma como los poderes políticos y económicos dominantes se relacionaban con los pueblos indígenas. Esta relación de dominio y desposesión territorial se agudizó con la expansión de los cultivos de exportación y su consecuente consolidación del modelo capitalista que trajo consigo una modificación las zonas comunales en donde habitaban los pueblos indígenas (Chacón y Guevara 1992).

Con esta consolidación del modelo económico, la expansión del Estado y del nacionalismo conservador y liberal, se fomentó la aculturación sustituyendo estructuras cacicales indígenas por nuevas expresiones de territorialidad, lo que implicó una versión negativa de las comunidades indígenas que, frente a la expansión del Estado, eran consideradas pueblos atrasados que debían integrarse -0 por lo menos sus tierras- al desarrollo y producción, en el cual:

[...] las relaciones entre sociedad dominante y pueblos indios se modificó sustancialmente, pasándose de un primer momento de exaltación patriótica que pretendió reconocer a estos pueblos como costarricenses con derechos civiles por lo menos iguales al de otros compatriotas, a la consideración de dicha población, ya entrado el siglo XX, bajo perspectivas neo-colonialistas, en que los indios volvieron a concebirse como aberraciones humanas destinadas a la extinción (Chacón y Guevara 1992, 45).

Como indican los autores, para el siglo XX continúa la visión del indígena como población improductiva, se adhería la intención de que debían ceder 
sus tierras para la generación de actividades económicas nacionales, sin que se privilegiara nunca un modelo compartido de convivencia con las tierras habitadas por pueblos originarios.

\section{Vestigios del territorio indígena}

Puesto que el territorio indígena, según apunta Bello $(2001,100)$, se encuentra cruzado de manera transversal por dos elementos: el de la identidad, que se sostiene sobre el contexto comunal cultural y su contexto natural; y por el ámbito de la política, en el sentido de la defensa de derechos y autonomía, es que ambos aspectos surgen como ejes defendibles desde los pueblos indígenas, siendo base de sus luchas.

La situación descrita, y siguiendo la perspectiva de recuento histórico, se encuentra que, en lo productivo, económico, social y político, en Costa Rica no hubo ningún cambio significativo hasta entrado el siglo $X X$, cuando, hacia el año de 1939, por primera vez en una legislación de la República, el Estado costarricense hace referencia a las tierras indígenas. En esta ocasión, la Ley General sobre Territorios Baldíos, N. ${ }^{\circ} 13$, se emitió que:

\begin{abstract}
Se declara inalienable y de propiedad exclusiva de los indígenas, una zona prudencial a juicio del Poder Ejecutivo en los lugares en donde existan tribus de éstos, a fin de conservar nuestra raza autóctona y de librarlos de futuras injusticias.
\end{abstract}

En esta mención se señala una zona para la tenencia de pueblos originarios que será reconocida como tierra inalienable y lugar para la protección de las culturas indígenas. Sin embargo, esta ley solo consideró la zona del Atlántico en Limón, sin incluir otros pueblos del país, como los ubicados en las provincias de Guanacaste, Alajuela y Puntarenas. Además, esta norma no evitó que las tierras indígenas siguieran siendo ocupadas por instancias del Estado, el mercado o la población no-indígena e incluso extranjera. ${ }^{1}$

El despoblamiento de las regiones indígenas ligado a la pérdida en la tenencia de sus tierras, debido a que la presión ejercida sobre estas seguía siendo el panorama principal que dominaba la escena nacional. ${ }^{2}$ Esta situación se mantuvo hasta que, en el año de 1956, se decretaron las primeras reservas indígenas que construían límites territoriales alrededor de centros de poblamiento indígena a quienes se les reservaban estas tierras para habitarlas y producirlas en exclusividad. Para ese año, mediante el Decreto $\mathrm{N} .^{\circ} 34$, se disponen las reservas indígenas de Boruca, Térraba, Curré y Ujarrás (Salitre y Cabagra) y China Kichá, en la parte sur de Costa Rica (Carls 2013).
1. Como fue el caso del poblamiento de la Zona Sur del país, en los cantones de Buenos Aires y Osa, que hubo varias llegadas de habitantes provenientes de la provincia de Chiriquí de Panamá, que, entre otros motivos, llegaron atraídos por las opciones laborales alrededor de la Compañía Bananera United Fruit Company, instalada en la zona; y proyectos de asentamiento con cultivos agrícolas o ganaderos, lo cual, en ambos casos, incluía la movilización de población indígena en territorios de menor tamaño (Marín, Bartels y Abarca 2011).

2. Fue dentro del conjunto de reformas sociales surgidas en

Costa Rica en la década del 1940, que se fueron vislumbrando más acciones estatales en su relación con los pueblos indígenas. Así, en la Constitución Política promulgada en noviembre de 1949, se otorgó Personería Jurídica a la Junta de Protección de Razas Aborígenes de la Nación, aun así, la desposesión no cesaba (Mendoza 2008). 
3. Esto a pesar de que, para el año de 1959, Costa Rica ratifica el Convenio 107 de la Organización Internacional de Trabajo (OIT), en cuyo acuerdo se conviene sobre derechos territoriales indígenas (Chacón 2001, 23).

\section{Así lo explica Carlos Mendoza, en la cronología legislativa de asuntos indígenas que construyó desde el 2008 y puso a disposición en el blog, \\ http://democraciamulticultural. blogspot.com/2008/05/costa-rica -legislacin-sobre-pueblos.html \\ 5. Según Mires (1991), es una de las posiciones que asume el indigenismo estatal y nacional.}

Estas tierras de reserva establecían límites étnicos decretados por el Estado que fungía como regulador de estas zonas. Sin embargo, el acercamiento hacia las tierras indígenas era escaso en cuanto a bienes públicos se refiere, lo que implicó un abandono institucional y social de las poblaciones indígenas que habitan estas tierras ${ }^{3}$. De igual manera, la gobernanza propia de sus figuras políticas tradicionales tampoco era concedida ni dialogada desde el Estado, y eran tierras adscritas y administradas por el Instituto de Tierras y Colonización (ITCO), creado en el marco de la Ley de Tierras y Colonización de 1961 , lo que les restaba a los indígenas el dominio propio de sus tierras. ${ }^{4}$

En tal escenario, se percibe una acción estatal tendiente a la delimitación limítrofe de zonas indígenas con poca interconexión cultural, económica, educativa, social y política con las poblaciones indígenas de estas tierras. No obstante, con el indigenismo integracionista, ${ }^{5}$ los pueblos indígenas debían ser integrados al sistema nacional para lograr su desarrollo, lo que implicaba mayor presencia estatal en las "reservas" y una pauta marcada desde el Estado para los cambios en los territorios. Fue este el marco en el que se crea la Comisión de Asuntos Indígenas (CONAI), bajo la ley N. 5251 (de 1973), como la institución que velaría por el desarrollo de estos pueblos.

Este enfoque integracionista de los pueblos indígenas al desarrollo (Mires 1991), se fortaleció como parte del proyecto del Estado como actor hegemónico en el territorio nacional, cuando, en 1977, se emite la Ley Indígena (N. ${ }^{\circ}$ 6172). Esta ley tenía una visión progresista para su momento, ya que esboza principios de autonomía y delimitación territorial, identidad étnica, prohibiciones para población no-indígena y una relación reglamentada entre instituciones del Estado y estructuras comunitarias indígenas internas (Chacón y Guevara 1992, 147).

Seguido de esta Ley - de la que se apropiarán las mismas poblaciones indígenas en luchas de defensa territorial, cultural e identitaria-, los nuevos cambios en lo referente a la territorialización indígena en Costa Rica se harían mediante los decretos de creación de nuevas reservas indígenas en el país: Guatuso y Keköldi en 1977; Quitirrisí en 1979; Abrojo Montezuma y Matambú en 1980; Coto Brus en 1981; Cabagra y Salitre, que se separarían de Ujarrás en 1982; Conte Burica y Zapatón, también en 1982; Tayni en 1984; Talamanca Cabécar, Talamanca Bribri y Telire en 1985 (Mendoza 2008; Guevara 2001).

Con la creación de estos decretos territoriales, hacia la década del ochenta, en Costa Rica se contaba con 21 zonas asignadas a pueblos indígenas según la figura de reservas. A pesar de estas delimitaciones territoriales, la relación entre Estado y pueblos indígenas planteaba designios coloniales desde la hegemonía de fuerzas gubernamentales sobre los territorios. En este contexto, las acciones mismas de lucha indígena en la defensa de sus condiciones culturales como pueblo y, específicamente, de autodeterminación política y territorial, no eran posibles por la institucionalidad existente que tampoco reforzaba su participación. Por este motivo, fue que las propias poblaciones indígenas aumentaron sus demandas de protección territorial, respeto cultural, identitario y de autodeterminación como pueblos. 


\section{Luchas y demandas de pueblos indígenas}

En este amplio contexto histórico-político de relaciones colonialistas y neocoIonialistas estatales y empresariales (Boaventura 2010), es que los pueblos indígenas han impulsado una agenda de lucha por el reconocimiento de derechos territoriales y de denuncia de la usurpación de estas tierras por parte de población no-indígena; lo que se convierte en el eje central en su agenda de lucha entre 1970 y el 2018.

Durante las décadas de 1970, 1980 y 1990, hubo una serie de demandas y luchas desde los territorios que fueron formando y consolidando una dirigencia indígena proveniente de todos los pueblos indígenas de Costa Rica. Lo anterior llevó a diferentes procesos de organización política surgida debido a las presiones sobre sus tierras por las relaciones de colonización, en algunos casos locales y en otras desde ámbitos más amplios y regionales, que fueron justificando la defensa del territorio desde la organización entre indígenas de distintos pueblos, adquiriendo una mayor participación indígena frente las acciones del Estado y el mercado. Al respecto, el historiador Juan Carlos Solórzano $(2011,4)$ explica que:

A principios de los años 80 , las comunidades indígenas de Talamanca se organizaron para rechazar una reforma al Código de Minería que iba a modificar el derecho de los indígenas sobre el subsuelo. Sin embargo, la reforma se aprobó eliminando a los indígenas de la co-propiedad del subsuelo que reconocía la Ley Indígena de 1977.

Esta lucha de los pueblos bribri y cabécar del Atlántico respondía a las tónicas del desarrollo nacional desde una lógica de defensa territorial frente las intenciones extractivistas de recursos naturales en los territorios indígenas que continuaban con procesos de colonización modernizante, ante lo cual estos pueblos vieron necesaria la defensa de sus territorios. En este contexto de la década de 1970, a causa de las acciones de indígenas bribris de Talamanca, se logró sacar a la petrolera AROL SINSON, la cual durante cuatro años utilizó dinamita para sus exploraciones y construyó campamentos (Cole 2009, 4).

Desde las décadas de 1970 y $1980,{ }^{6}$ hay registro de proyectos de producción de energía hidroeléctrica con intervenciones del Instituto Costarricense de Electricidad (ICE) en las cuencas de los ríos Sixaola y Pacuare, ubicados dentro o muy cerca de territorios indígenas. En la cuenca del Sixaola se han contabilizado 16 proyectos, donde el de mayor importancia, por la energía que produciría, inundaría hasta 11500 hectáreas, afectando cerca del 80\% de la población bribri; mientras que en la cuenca del Pacuare se han identifi-
6. En distintas crónicas de exploradores como las de William Gabb, se detallan exploraciones mineras desde el año de 1863; así como en 1884 , cuando se firmó el contrato Soto-Keith, en el que el Gobierno de Costa Rica concedió 800000 acres en tierras baldías a Minor Keith a cambio de terminar el ferrocarril al Atlántico, la mayoría de estas eran tierras indígenas. Además, en 1909, con el ingreso de la Chiriquí Land Company (CLC) se produjo un fuerte impacto en el ecosistema talamanqueño, modificando el paisaje y la territorialidad indígena, debido al ingreso del monocultivo, las llanuras y el bosque son desplazados por abundantes plantaciones de banano. Este impacto en el territorio indígena también tuvo la reacción de clanes con importante representación espiritual que se refugiaran cada vez más montaña adentro. 
7. Así se le llama al grupo de líderes espirituales que intervienen cuando hay crisis, sociales y naturales que afectan a las comunidades indígenas.

8. Esta intervención de los usékölpa puede ser ampliada en el libro: Salas Díaz, Uri. 2016. Las inundaciones y el Siwâ. Acercamiento a la historia ambiental de Talamanca. EUNED, Costa Rica. En esta publicación se explican este tipo de intervenciones, además de cambios culturales, sociales y económicos que se fueron produciendo en los territorios bribris y cabécar de esta región. Entre otros, se menciona que cuando el nivel del agua bajó con los ríos más anchos por la modificación que habían recibido, parte de la mano de obra indígena se incorporó a las nuevas labores económicas que sucedieron cambios significativos en las formas de organización social bribri, como lo fue la

"chichada". Uri Salas Díaz también explica que la vivienda y el asentamiento de las familias indígenas tendió al abandono del usuré, que por presión de no indígenas que argumentaban era inseguro para las familias, se fueron sustituyendo por la construcción de casas de madera sobre pilotes, lo que desplazó el simbolismo y los significados presentes en la casa cónica, además de generar un aumento en la tala de árboles para tales fines.

9. En el Valle Central están los territorios de Zapatón y Quitirrisí, donde habita el pueblo huetar; mientras que hacia el norte, en las llanuras de San Carlos, está el territorio Guatuso del pueblo Malecu, y en Guanacaste, se encuentra el territorio Matambú del pueblo chorotega. cado 5 proyectos, los cuales afectarían también a territorios cabécar (Cole 2009).

Además, en la década de 1990, según Jorge Cole (2009, 4-5), se dieron nuevos intentos de extracción minera como el propiciado por el empresario Ray Carson, iniciativa que fue rechazada por los pueblos indígenas afectados, los cuales lo expulsaron. De igual forma, en 1998, el Ministerio de Ambiente y Energía (MINAE) otorgó una concesión para la exploración y explotación minera a las empresas MKJ XPLORATIONS y HARKEN COSTA RICA HOLDINGS; el rechazo indígena a estas empresas se justificó -entre otros- por incumplir el proceso de consulta con los territorios, además, en el año 2000, estas concesiones fueron anuladas por la Sala Constitucional mediante el voto 2000-8019 (Cole 2009, 4). Estas acciones de defensa territorial, en el caso de los indígenas talamanqueños, también han sido reconocidas por la bravura de su carácter y por ser guerreros que históricamente han librado batallas donde los liderazgos políticos y espirituales son parte concomitante de su dirigencia, siendo características inseparables en las luchas de estos pueblos.

Esta relación político-espiritual identificada desde luchas emprendidas por los usékölpa ${ }^{7}$ en su intervención para detener el impacto del extractivismo y la explotación de la tierra con las llenas de ríos entre 1920-1935, las que produjeron algunas pozas que posteriormente se derrumbaron ocasionando grandes cabezas de agua, que fueron parte -según la memoria oral y algunas fuentes bibliográficas- de las razones por las que los proyectos de intervención extractivista abandonaron la zona. ${ }^{8}$

El carácter aguerrido de estos siguió propiciando mayores niveles de organización en asociaciones civiles, velando por los derechos territoriales de sus pueblos y la protección de la naturaleza. Según mencionan Borge y Villalobos (1998, 101):

\section{Los Awapa pasaron a controlar la cuestión religiosa y de} resguardo de las tradiciones; también intervinieron en los asuntos de políticos de las comunidades. Los Ikekepa o señores principales, algunos de ellos pertenecientes a los clanes de jefes militares, asumieron los asuntos políticos.

Este aumento en el nivel organizativo de los territorios bribris y cabécares se refleja en las más de 150 organizaciones civiles indígenas, agrupadas en la asociación CODEBRIWAK en 1990, bajo una activa resistencia autonómica que buscaba mantener a personas e instituciones alejas fuera de este territorio (Guevara Víquez, 2011, 56). Sin embargo, los procesos de luchas y defensa territorial no han sido exclusivos de los pueblos indígenas de Talamanca, ya que estas y otras luchas han estado presentes en otros territorios indígenas de Costa Rica ubicados, principalmente, en la Zona Sur del país, pero también en la Región Norte y la Región Central. ${ }^{9}$ En este contexto de luchas 
de defensa territorial indígena, hacia las décadas de 1980 y 1990 las propuestas indígenas fueron de vanguardia, empujando al Estado hacia una mayor asignación de derechos colectivos indígenas que vendrían a amalgamar a los pueblos indígenas bajo consignas de peso político, las que incluso ocuparían varios años o décadas de lucha.

Una de estas luchas indígenas fue la demanda de cedulación del pueblo ngäbe, para que se les reconociera como costarricenses por nacimiento y no como extranjeros. Esta lucha, emprendida entre 1990 y 1991, apelaba a una solución sobre la condición civil de las y los habitantes de pueblo ngäbe, quienes, al estar en territorios a ambos lados de la frontera entre Costa Rica y Panamá -y por ende en ambos países- tenían problemas para su movilidad e inserción social en el territorio costarricense, pues se les concebía como panameños a pesar de que históricamente han habitado tierras de cantones como Corredores, Coto Brus, Golfito y Osa, por cientos de años (Zúñiga et al., 2014).

En esta lucha, ${ }^{10}$ la organización creada para dicho fin, Asociación Cultural Ngöbegue, impulsó una protesta que llegaría a los principales poderes del Estado -incluyendo movilizaciones indígenas en Ciudad Neily y San Josépara que se les ratificara su condición de ciudadanía costarricense por nacimiento. A esta lucha se unieron indígenas de los pueblos térraba, brunka y cabécar que apoyaron la demanda.

Finalmente, y luego de meses de presión de la Asociación Ngöbegue, el Estado emitió la Ley N. ${ }^{\circ}$ 7225, decretada por la Asamblea Legislativa en 1991, siendo la solución a esta petición indígena (Zúñiga et al. 2014). Esta lucha por la cedulación fortaleció la organización indígena que de inmediato llevó a cabo dos peleas más en el año de 1992: la primera, presionar por cambiar el 12 de octubre denominado "Día de la Raza" para nombrarse de una manera menos discriminatoria, pasando a llamarse "Día de las Culturas" (Solórzano 10. También fue apoyada por la Asesoría Nacional Indígena (ANEIN) del Ministerio de Educación, la motivaban las dificultades que tenían las y los ngäbes ante la justicia

costarricense, las escuelas, la inscripción en organizaciones nacionales, la constante 2011).

La otra demanda importante, luchada y lograda por el movimiento indígena, fue la presión para que el Estado costarricense ratificara el Convenio 169 de la OIT sobre Pueblos Indígenas y Tribales, el cual ampliaba los compromisos que los Estados debían asumir en relación con los pueblos indígenas. Entre las varias reformas que se incorporaban en este Convenio de 1989 estaban el posicionamiento del "territorio" indígena como derecho colectivo sobre sus tierras, lo que, a su vez, propiciaba mecanismos para la gobernanza propia de cada pueblo según sus tradiciones y sustituía el concepto de "reservas indígenas" por el de "territorios indígenas", en el que se asignan derechos políticos y de control territorial y cultural de estos.

Esta segunda lucha comprobaba la necesidad de reforzar el marco jurídico y político para con los pueblos indígenas, enfoque que el propio movimiento indígena quiso profundizar al punto de que, en 1992, 1993 y 1994 comenzaron con un proceso interno para la formulación de un proyecto de ley que les reforzara sus condiciones como pueblos autónomos. Así, se redactó el Proyec- 
11. Desde 2008, el gobierno costarricense decide sumarse a una experiencia liderada por el Fondo Cooperativo para el Carbono de los Bosque que busca fomentar sistemas y políticas para REDD+.

12. Reducción de emisiones por deforestación y degradación del bosque más la conservación/gestión sostenible de los bosques y aumento de las reservas de carbono forestal.

13. Surcos Digital. 2016. "Comunidades bribris de Talamanca entregan declaratoria territorial contra REDD+". 28 junio. Acceso 7 agosto 2018.

https://surcosdigital.com/comuni dades-bribris-de-talamanca-entre gan-declaratoria-territorial-con tra-redd/

14. Noguera Jarmon. 2015 Indígenas se plantan frente a Casa Presidencia, 15 octubre. Acceso 8 agosto 2018. http://www.laprensalibre.cr/not cias/detalle/43579/419/indigenas -se-plantan-frente-a-casa-presid encial

15. Asistieron personas de las comunidades de Kachabli, Amuble, Katsi, Durupe, Soki, Alto Coen, Alto Urén, Alto Dúriñak, Arenal, Sepecue, Kloma, Suretka, Meleruk, Tsuiri, Watsi, Bajo Coen, Mojoncito, Yorkin, Kekoldi, Kórbita, Orochico.

16. Voces Nuestras. 2016. Comunidades bribris de Talamanca piden ser territorio libre de REDD+, 4 de julio, Acceso 4 agosto 2018.

http://www.vocesnuestras.org/20 16-07-04/articulo/comunidades-b ribris-talamanca-piden-ser-terr itorio-libre-redd to de Ley de Desarrollo Autónomo de los Pueblos Indígenas (PDLDAPI) en su primera versión bajo el expediente N. ${ }^{\circ} 12032$ (Arias et al. 2016).

Otra de las luchas indígenas recientes, desde el $2010,{ }^{11}$ ha sido contra REDD,$+{ }^{12}$ esto es, un proyecto del Fondo Nacional de Financiamiento Forestal (FONAFIFO), MINAE, financiado por el sector empresarial y el Banco Mundial, el cual busca que grandes corporaciones "compensen" la contaminación que realizan, en otras palabras, que paguen para seguir contaminando. La oposición REDD+ por parte de varios pueblos originarios -en especial del pueblo bribri- se debe a que lo conciben como una amenaza para su modo de vida, limitando el uso del bosque para que las familias realicen actividades como la recolección y cultivo de subsistencia. ${ }^{13}$

Según nota del periódico La Prensa Libre, el 15 de octubre de $2015,{ }^{14}$ un grupo de indígenas llegó a las afueras de Casa Presidencial con el fin de exigir que se respetaran el Convenio 169 de la OIT y la Declaración de las Naciones Unidas sobre los Derechos de los Pueblos Indígenas (2007). De igual manera, el 1 de julio de 2016, un grupo de 400 personas de 23 comunidades bribris $^{15}$ se reunieron en Suretka para presentar públicamente una declaratoria de Territorio Bribri Libre de REDD+, mecanismo construido por este pueblo originario para defenderse ante el avance de dicha estrategia. Para marzo de ese mismo año, el gobierno dio por terminadas las etapas de información y preconsulta, esto sin que las comunidades las aprobaran. ${ }^{16}$

\section{Proyecto de Ley Desarrollo Autónomo de los Pueblos Indígenas}

Como antecedente de la lucha por la aprobación del Proyecto de Ley de Desarrollo Autónomo N. ${ }^{\circ} 12032$, en la década de los ochenta y noventa en Costa Rica se vivía un ambiente de luchas indígenas en temas como la usurpación de territorios, e incluso se formó un expediente N. ${ }^{\circ} 9858$, la Comisión Especial que Investiga la Usurpación de Tierras Indígenas (Blanco, Pérez, Solano y Torres 2010).

En dicho contexto, un primer acercamiento al Proyecto de Ley de Desarrollo Autónomo (PDLDAPI) se realiza el 11 de noviembre de 1992, cuando se efectúa una reunión en la que se presenta un proyecto de ley que buscaba "apoyar a los grupos indígenas étnicos para conseguir su semiautonomía", según consta en la redacción del mismo proyecto. En esta reunión participó un grupo de líderes indígenas. Se destaca que los indígenas con los que trabaja en este primer paso son aquellos quienes han tenido cierta participación a nivel político, tanto en sus comunidades como fuera del país y con algún conocimiento del manejo legislativo y de la institucionalidad pública del Estado costarricense.

Al año siguiente, el 27 de enero de 1993, la dirigencia indígena de diferentes comunidades y organizaciones indígenas, algunos representantes del Consejo Mundial de Pueblos Indígenas y del Instituto Interamericano de Derechos 
Humanos, se propone unir los expedientes N. 9858 "Informe unánime de la Comisión Especial que investiga la usurpación indígena", el N. 9956, "Proyecto de Ley contra usurpaciones de terrenos en reservas indígenas" y el "Proyecto de Desarrollo de las Comunidades Indígenas". En octubre del año de 1993, recibe el informe de subcomisión afirmativo de mayoría y el 22 de noviembre de 1994 es publicada en La Gaceta N. ${ }^{\circ} 222$ (Arias et al. 2016, 71).

Una vez definido el proceso de consulta, en el cual la Mesa Nacional Indígena (MNI) tuvo un papel de guía, se elaboró un reglamento para la consulta que se inicia en 1997, entre los meses de julio y agosto de ese año, con una serie de talleres en las comunidades donde se discutía y se le elaboraban observaciones al articulado del proyecto. En dichos talleres se eligió a un delegado que representaría a cada territorio en lo que se llamó el Foro Nacional Indígena, realizado entre el 22 y 27 de setiembre de $1997^{17}$ (Arias et al. 2016, 78).

En 1998, se presenta la Consulta Facultativa de Constitucionalidad, para conocer si tiene algún conflicto con la Constitución Política, y la Sala IV dicta que dicho proyecto no tiene inconstitucionalidades. El proyecto es aprobado en primer debate en plenario por 37 de 40 diputados presentes en la sesión (Arias et al. 2016, 89).

Sin embargo, para el segundo debate el proyecto es archivado debido a la fuerte presión de la Comisión Nacional de Asuntos Indígenas (CONAI) que estuvo en contra del proyecto porque la Ley eliminaría esta institución adscrita al Poder Ejecutivo. Además, para 1998 -con un nuevo Gobierno en el poder- algunos políticos que venían impulsando el proyecto ya no estaban, por lo tanto, nuevas alianzas políticas entre diputados entorpecieron su discusión y aprobación, ello generó que en el año 2000 se archivara (Arias et al. 2016, 92).

El proyecto de ley es retomado en el 2001 y se le asigna un nuevo número, N. ${ }^{\circ} 14352$, pero en los siguientes cuatro años el proyecto no tiene mucho movimiento. La Mesa Indígena Nacional y el Frente Nacional de Pueblos Indígenas presentaron un informe a la Comisión Interamericana de Derechos Humanos, como consecuencia, logran que se certifique el estado del proyecto y se dan cuenta de que iba a ser archivado en el 2005, cuando se logra que algunos diputados realicen sesiones de trabajo para reimpulsar el texto. ${ }^{18}$ Se destaca que, en el 2005, se desarrolla nuevamente un proceso de preconsulta y consulta con indígenas y la Comisión de Asuntos Sociales nombra a la Mesa Nacional Indígena como facilitadora (Arias et al. 2016, 93-94). Sin embargo, hubo sectores indígenas y no indígenas opuestos al PDLDAPI, conformado por algunos indígenas, funcionarios(as) de CONAI, y políticos con intereses personales en la zona. En los territorios indígenas, las y los promotores de CONAI han estado aliados con los no indígenas, dando constancias de posesión de tierra a población no indígena. Esta oposición de la CONAI, que se supone es una institución que debe velar por los derechos de los pueblos indígenas, argumentaba que ya existía la normativa necesaria en
17. El resultado del foro fue un documento que contenía mejoras en el texto y el parecer de los delegados que sesionaron como diputados y es entregado en un acto formal a un representante de la Subcomisión que estudiaba el texto en la Comisión de Asuntos Sociales. Obteniendo voto favorable en primer debate.

18. Una vez realizados los procesos de consulta, el proyecto se devuelve a comisión legislativa sin plazo, esto debido al juego político alrededor de un error material en el que se comete en el artículo 8 del texto, el cual buscaba la modificación del artículo 5 Ley de Simplificación y Eficiencia Tributarias N. ${ }^{\circ}$ 8114 del 4 de julio de 2001 (Arias et al. 2016). 
19. Entre los diputados que mantenían esta postura estaba Ottón Solís Fallas. Para detalles, ver

http://www.diarioextra.com/Noti cia/detalle/254782/retiran-delplenario--proyecto-de-autonomia

20. Las ADI, como estructura de representación de las comunidades indígenas, se encuentran presentes en todos los territorios en la nación, por tanto, no contempla, necesariamente, las particularidades culturales de los pueblos indígenas ni las formas de organización que han sido utilizadas por los pueblos originarios, siempre apoyados y basados en la sabiduría de sus Mayores. materia de estos derechos, pero, en el fondo, ocurre que CONAI desaparecería con la aprobación de esta ley, dando lugar a los Consejos Territoriales.

Entre los argumentos en contra, algunos políticos establecían que este proyecto generaría "un país dentro de otro", es decir, un estado autónomo dentro de otro, cosa que nunca ha sido expresada por el grupo a favor del proyecto. ${ }^{19}$ Sobre este aspecto, Blanco y otros $(2010,50)$ mencionan que esta negativa al PDLDAPI se argumentaba como separatismo y desarticulación del Estado. Cabe destacar, también, que de fondo hay una disputa por la representatividad y la pérdida de poder, la cual tendrían que asumir tanto la CONAI como las $\mathrm{ADI}$ en los territorios indígenas. ${ }^{20}$ Además, los autores recién mencionados, identifican una división en tres sectores: el primero, la Sociedad civil indígena organizada y en apoyo, conformada por la Mesa Nacional Indígena (MNI), que para este proyecto fue un ente de coordinación de acciones apoyo, divulgación y consulta; FRENAPI, que se encargó de la movilización y organización de líderes indígenas en los territorios; y la Asociación Regional Aborigen del DIKES (ARADIKES) realizó labores de facilitación, información, divulgación y apoyo logístico. También, en este primer grupo, se encuentran una serie de asociaciones indígenas, entre ellas: Asociación de Mujeres de Indígenas de Talamanca (ACOMUITA), Asociación de Mujeres Mano de Tigre (Térraba), Asociación de Mujeres Huetares de Quitirrisí, Asociación para la Defensa de los Derechos Indígenas (ASODIN), Asociación Cultural Ngäbegue. Mencionan los autores que, además, participaron juntas y comités, así como diversas ONG de distinta naturaleza, aliados a los indígenas.

En el segundo grupo, La institución estatal con dirigencia indígena en contra de la propuesta, que era encabezado por la CONAI, la cual rechazó la propuesta junto con las ADI que actuaron como aliados. El tercer grupo, La sociedad civil indígena que no se encuentra formalmente organizada, conformada por personas de las comunidades que no conocían los contenidos del proyecto de ley que, sin embargo, según Blanco y otros (2010), no necesariamente significaba que no estuvieran a favor de la reivindicación de derechos y mejoras en la calidad de vida indígenas. Por otro lado, estaba la postura de profesionales cercanos a las temáticas indígenas que se mantuvieron en contra del PDLDAPI, como fue el caso del exjuez agrario, Danilo Chaverri, para quien es innecesario instrumentalizar el Convenio 169 de la OIT con la ley de desarrollo autónomo, puesto que el Convenio es superior a una ley nacional. Además, para este abogado, el proyecto podría ser peligroso en dos aspectos: el territorio y la organización política.

El territorio debido a que podría haber problemas reconociendo zonas de uso ancestral que entraran en contradicción con la actual Ley Indígena, permitiendo la ampliación de los territorios, pero no su reducción; y en la organización política, ya que los procesos de expropiación de tierra en manos de no indígenas se realizarían -según Chaverri- de una manera segura y efectiva de acuerdo con la Ley Indígena, lo que no se garantizaría mediante el proceso de compra establecido en el PDLDAPI (Chavarría et al. 2013).

Además, en cuanto a la organización política, Chavarría y otros (2013), mencionan que la postura de Danilo Chaverri argumentaba que los Consejos In- 
dígenas Territoriales vendrían a ser una nueva especie de ADI, pues no se establece el mecanismo para garantizar que este nuevo órgano indígena fuera a tomar en consideración las decisiones de la colectividad dentro de los pueblos.

Pese a las posiciones divergentes alrededor del PDLDAPI, la lucha por la ley de autonomía se puede comprender de una mejor manera en el cuadro 1, en el que se relatan algunas de sus etapas y disputas asociadas.

Cuadro 1. Luchas indígenas por la aprobación del Proyecto de Ley de Desarrollo Autónomo de los Pueblos Indígenas

\begin{tabular}{|c|c|}
\hline Años & Acciones al proyecto de ley de autonomía indígena \\
\hline $1992-1994$ & $\begin{array}{l}\text { El movimiento indígena impulsa la revisión del proyecto desde los } \\
\text { territorios }\end{array}$ \\
\hline 1995 & Proceso de participación con representantes indígenas de territorios \\
\hline 1997 & $\begin{array}{l}\text { Entre julio y setiembre se hacen } 35 \text { talleres en los que se sometió a } \\
\text { discusión el texto con indígenas en la Asamblea Legislativa }\end{array}$ \\
\hline 1998-2000 & Caminatas desde la zona sur hasta Casa Presidencial. Una por año \\
\hline 2000-2001 & El proyecto se archiva y se retoma con nuevo número de expediente \\
\hline $2001-2005$ & Proceso interno en la Asamblea Legislativa y presión de los pueblos \\
\hline 2005-2006 & Nuevo proceso de participación en territorios indígenas \\
\hline 2007-2008 & Ingresa a discusión a primer debate en Plenario \\
\hline 2008 & Meses de vigilias indígenas fuera de la Asamblea Legislativa \\
\hline 2009 & Vuelve al primer debate en Plenario \\
\hline 2010 & En agosto se da el desalojo violento de la Asamblea Legislativa \\
\hline 2010-2014 & El proyecto de ley de autonomía se estanca en la discusión \\
\hline 2014 & El Gobierno vuelve a colocar el proyecto para su discusión \\
\hline 2017 & Continua en la corriente legislativa sin prioridad ni discusión \\
\hline
\end{tabular}

Elaboración propia

En este contexto de presión por aprobar el PDLDAPI, en el año 2012, en un acto simbólico, un grupo de dirigentes indígenas entregan la "Cédula de la Desvergüenza", que representaba la mayoría de edad del proyecto de ley que ya había cumplido 18 años de estar estancado en la corriente legislativa sin que se diera ningún tipo de dictamen definitivo. ${ }^{21}$ No obstante, el grupo a favor de la aprobación de esta ley siguió presionando para que se votara y, sin que esto se diera, el texto fue retirado de las sesiones extraordinarias en el 2015 y actualmente, en el año 2018, el proyecto sigue estancado, sumando 23 años en la corriente legislativa, lo que implica una postergación estatal 21. Para conocer en detalle sobre este evento, ingresar a las siguientes noticias: https://elperiodicocr.com/indi genas-confieren-a-la-asambleaqcedula-de-la-desvergueenzaq/ en la asignación de los derechos indígenas. 
22. Aunque las primeras acciones organizativas en esta línea comenzaron desde el año 2002, pasando en el año 2003 con un primer grupo llamado Foro Nacional de Pueblos Indígenas (FONAPI).

23. Varios de estos talleres estuvieron orientados a estudiar en mayor profundidad la legislación nacional e internacional relacionada con pueblos indígenas, realizando, entre otros, en las siguientes comunidades indígenas: Rey Curré, Ujarrás, Amubri, Nairí Awari y territorios indígenas de Tayni, Salitre, Térraba, La Casona, Alto San Antonio, Abrojo Montezuma, Conte, Ujarrás, Quitirrisí (Quesada 2017, 129).
Se destaca que, desde el inicio de los años 2000, varios y varias dirigentes indígenas emprendieron un proceso de fortalecimiento organizativo que, hacia el año 2004, se canalizó con la creación del Frente Nacional de Pueblos Indígenas $^{22}$ (FRENAPI), que aglutinando dirigencia indígena de varios territorios -centralmente del sur del país- se constituyó como un solo grupo de conducción política relacionado con la agenda del PDLDAPI y otras demandas políticas, orientadas hacia la capacitación y movilización (Quesada 2017, 128).

Este colectivo indígena se ha mantenido constante en el tiempo, siendo referente de la lucha indígena desligada de las plataformas de CONAI y las ADI, manteniéndose como colectivo orientado a lograr la autonomía indígena que ha tenido auspicio y respaldo de la organización no gubernamental Servicio de Paz y Justicia (SERPAJ), que colabora con la logística de su organicidad y es parte compartida de las reflexiones, talleres de capacitación ${ }^{23}$ e incidencia política que consecutivamente fueron realizando desde el año 2004 hasta el 2018 (Quesada 2017, 129-138).

Según se desprende del proceso de sistematización que FRENAPI realizó guiado desde sus propios integrantes con el apoyo de SERPAJ, y documentado por el investigador David Quesada García (2017), la organización ha tenido como temas prioritarios las luchas por gobiernos propios y estructuras ancestrales; recuperación de tierras-territorio; identidad cultural y aplicación de Derechos Indígenas. De esta manera, las apreciaciones referidas alrededor de las acciones acerca de la presión hacia la Asamblea Legislativa en torno al PDLDAPI fueron posibles desde el impulso que desde FRENAPI se acordaba, acciones que, como ya se mencionó, seguirían continuas hasta la actualidad en el 2018.

\section{Desalojo violento y la lucha desde los territorios}

Entre los años 1994 y 2000, la presión política de parte de los pueblos indígenas a favor del Proyecto de Ley de Desarrollo Autónomo, se siguió expresando con la realización de caminatas en 1998, 1999 y 2000 desde la Zona Sur hacia la capital, donde acudieron a la Casa Presidencial para hacer presión (Brenes 1998; Rivera 1999). Bajo esta consigna, decenas de indígenas caminaron hasta $300 \mathrm{~km}$ desde la Zona Sur a la Casa Presidencial, sin embargo, dichas protestas y reuniones con actores de la política nacional y el gobierno no dieron los resultados esperados y el proyecto siguió estancado.

La lucha indígena se mantuvo constante, y en el año 2008, indígenas de todos los pueblos realizaron una vigilia frente a la Asamblea Legislativa y durante ocho meses, en toldos con información, presionaban por la aprobación de la Ley de Desarrollo Autónomo, acciones cuyo "resultado fue una absoluta invisibilización por parte del Estado y del Parlamento", según afirman Zúñiga Muñoz y otros $(2014,230)$. Sin embargo, la demanda de Ley de Autonomía 
seguía siendo el eje de la lucha indígena, pues cubría los aspectos relevantes para la vida de los pueblos indígenas desde contenidos como los siguientes: 1. Consejo Territorial; 2. Desarrollo sostenible y desarrollo de la tierra; 3. Medicina natural y servicios de salud; 4. Educación pluricultural; 5. Vivienda, caminos y medio ambiente en territorios indígenas; 6 . Fondo de desarrollo indígena y sistema de crédito; 7 . Producción en los territorios indígenas de recursos naturales; 8 . Sobre los Consejos Indígenas; 9. Derecho consuetudinario; y 10. Disposiciones generales (Expediente Legislativo N. ${ }^{\circ} 14$ 352).

Debido a la importancia que varios grupos indígenas le otorgaban a este proyecto, continuaron las manifestaciones para presionar por su votación hasta que tuvo un punto de cambio entre el 9 y 10 de agosto del 2010. En esta ocasión, varios líderes y lideresas indígenas participan en unas actividades en la Asamblea Legislativa con motivo de la celebración del Día Internacional de los Pueblos Indígenas. Para dicho evento, representantes indígenas de diferentes pueblos fueron invitados e invitadas para dar algunas palabras, lo cual hicieron. ${ }^{24}$ Sin embargo, ante 16 años sin aprobación del proyecto de autonomía, las y los indígenas decidieron "tomar" la Sala de Expresidentes de la Asamblea Legislativa como una forma de presión para la resolución del PDLDAPI. Ante esta acción indígena en la Asamblea Legislativa, las autoridades políticas decidieron intervenir con las fuerzas de seguridad interna del Parlamento y la policía nacional, situación que se tornó compleja ante la resistencia pacífica de indígenas, quienes fueron arrastrados mediante el "desalojo violento", tal cual se recuerdan a estos eventos.

Este desalojo violento marcó la lucha, pues la dirigencia indígena presente decidió que las siguientes acciones de defensa territorial se harían desde los mismos territorios. En este punto, las y los indígenas decidieron retirarse del Valle Central y ejercer la autonomía desde sus comunidades argumentándola desde los marcos jurídicos de la Ley Indígena de Costa Rica N. ${ }^{\circ}$ 6172, el Convenio 169 de la OIT y la Declaración de las Naciones Unidas sobre los Derechos de los Pueblos Indígenas, del 2007, en los que se ratifican los derechos territoriales y el ejercicio de la autodeterminación de los pueblos.

Con este nuevo posicionamiento del movimiento indígena, la dirigencia del territorio bribri de Salitre comenzó con procesos de recuperación de tierra desde el mismo 2010. Esta lucha se extendería y tendría diversos momentos del conflicto tendiente hacia una mayor participación de recuperadores y recuperadoras entre los años 2011 y 2013 , período en el que se realizan varias recuperaciones del territorio de Salitre que estaban en posesión de población no-indígena (Sancho 2013).

Las recuperaciones de tierra en Salitre se sostenían sobre el argumento de la legislación mencionada y en sus momentos iniciales fue respaldada por su Asociación de Desarrollo Integral Indígena (ADII) que estaba conformada por indígenas bribris decididos y decididas a hacer valer sus derechos territoriales. En esta lucha, la violencia contra indígenas ha tenido una serie de manifestaciones que ha implicado la quema de las casas de indígenas recuperadoras(es), agresiones físicas y disparos. No obstante, en el año 2014, las re-
24. Este desalojo fue ampliamente cubierto por las noticias nacionales, incluso hay una serie de videos colocados en el portal YouTube con grabación en el momento de la arrastrada y los momentos de tensión. Varias organizaciones de derechos humanos y cercanos al movimiento indígena también estuvieron presentes y en sus portales tienen videos o documentos probatorios de este lamentable suceso. Para una referencia directa en la que se resumen los hechos, consultar el portal del Programa Kioscos Ambientales de la Universidad de Costa Rica, que, entre otros, se puede consultar en este enlace:

http://kioscosambientales.ucr.ac .cr/noticias/noticias-ambientale s/507-fuerza-publica-desalojo-po r-la-fuerza-a-indigenas-de-asamb lea-legislativa-de-costa-rica.ht $\mathrm{ml}$ 
cuperaciones se reforzaron extendiéndose por varias comunidades del territorio de Salitre. Esta lucha de recuperación de tierras siguió durante los años 2015 y 2016, manteniéndose vigente hasta la actualidad (Guerrero 2016). En estas recuperaciones de tierra en Salitre, los distintos poderes del Estado han mantenido una acción ambigua que no atiende las demandas propuestas por las y los indígenas, ni vela por el cumplimiento pleno de los derechos territoriales. En este conflicto, la dirigencia de los territorios de Salitre y Térraba ha interpuesto una denuncia ante la Comisión de la Corte Interamericana de Derechos Humanos -aún mantiene vigente contra el Estado costarricense-, apelando el incumplimiento del Estado en la protección de los derechos internacionales indígenas, la cual, desde abril del 2015 la CIDH ha llamado a cuentas al Estado costarricense que, sin mostrar avances al respecto.

Con esta experiencia de recuperaciones de territorio entre el 2010 y el 2017, las y los indígenas de Salitre han logrado volver a tierras que les pertenecían a sus familiares y que estaban en manos de población no-indígena. Este tipo de lucha de recuperación territorial, que siempre ha sido apoyada por indígenas de otros pueblos, también se ha venido realizando en el territorio bribri de Cabagra entre los años 2016-2018. (Oreamuno 2016).

Las recuperaciones de tierra en Salitre y Cabagra, pese a los actos de violencia sufridos y los procesos judiciales relacionados, lo cual torna complejo el panorama de la lucha, también fue replicado en dos ocasiones en el territorio bröran de Térraba, una ocasión en el 2014 y otra en el 2018 (Bermúdez 2018); con este último, completan un escenario de acción directa en la defensa del territorio mediante la recuperación de la posesión de la tierra en manos indígenas, trayendo consigo una serie de movilizaciones en la zona sur del país y modificando las relaciones entre pueblos indígenas y el Estado mediante la ejecución directa del ejercicio de autonomía.

De esta manera, en el contexto que surge luego del Desalojo Violento en el 2010, ha surgido una constante acción de vanguardia indígena ante una institucionalidad estatal lenta y poco inclinada hacia la resolución del conflicto desde los marcos jurídicos nacionales e internacionales indígenas que rigen en el país; siendo este un escenario de incumplimiento estatal en la garantía de la territorialidad indígena.

Con lo descrito, se muestra una continuidad de luchas indígenas en defensa territorial como un proceso histórico de varias décadas, en la cual, los pueblos indígenas han variado sus formas de lucha y demandas de derechos. En el cuadro 2, se muestra este conjunto de eventos de la lucha indígena. Lo que se desprende de este cuadro es la constancia en acciones de luchas indígenas relacionadas con asuntos de diversa índole, según sus capacidades de organización política en la demanda de distintos tipos de derechos, defensa del territorio y la búsqueda de vías que permitan un autogobierno tradicional. 
Cuadro $\mathrm{N}^{\circ}$ 2. Luchas y demandas del movimiento indígena

\begin{tabular}{|c|c|}
\hline Años & Acciones de lucha indígena \\
\hline 1985 & Resistencia indígena contra tala de madera en el territorio de Térraba \\
\hline 1985 & Proyecto de Ley Contra la Usurpación de Tierras Indígenas \\
\hline 1985 & Creación de la Asesoría Nacional Indígena \\
\hline $1990-1991$ & Lucha por la cedulación del pueblo ngäbe de Costa Rica \\
\hline 1992 & $\begin{array}{l}\text { El Estado de Costa Rica firma del Convenio } 169 \text { de la OIT por } \\
\text { presión indígena que demandaban esta vinculación }\end{array}$ \\
\hline 1992 & $\begin{array}{l}\text { Declaración del Día de las Culturas, que sustituye el Día de la Raza. } \\
\text { Esto debido a la presión indígena }\end{array}$ \\
\hline 1992-1993 & $\begin{array}{l}\text { Proceso de fomulación del Proyecto de Ley Desarrollo Autonomo de } \\
\text { los Pueblos Indígenas (PDLDAPI), por parte del movimiento indígena }\end{array}$ \\
\hline 1994 & $\begin{array}{l}\text { Presentación del Proyecto de Ley Desarrollo Autonomo de los } \\
\text { Pueblos Indígenas, en la Asamblea Legisaltiva No } 12032\end{array}$ \\
\hline 1994-1998 & Presión por la aprobación del PDLDAPI \\
\hline 1998-2000 & Caminatas de presión política sobre el PDLDAPI \\
\hline 2001-2008 & $\begin{array}{l}\text { Vigilias, marchas y presión por la aprobación del PDLDAPI, bajo el } \\
\text { expediente } N^{0} 14352\end{array}$ \\
\hline 2007-2008 & $\begin{array}{l}\text { Discusión en primer debate del PDLDAPI. Aprobado. No se realizó el } \\
\text { segundo debate y el proyecto vuelve a la corriente legislativa }\end{array}$ \\
\hline 2010 & $\begin{array}{l}\text { Desalojo violento de indígenas de la Asamblea Legislativa, que } \\
\text { presionaban por la votación del PDLDAPI }\end{array}$ \\
\hline 2011 & $\begin{array}{l}\text { Tribunal Contencioso Adminitrativo dicta sentencia que permite } \\
\text { recuperar } 4500 \text { ha ocupadas por no indígenas en Keköldi }\end{array}$ \\
\hline 2011 & $\begin{array}{l}\text { Recuperación del territorio Guatuso y el acceso al Refugio Nacional } \\
\text { de Vida Silvestre Caño Negro, con acceso para fines tradicionales }\end{array}$ \\
\hline 2011 & $\begin{array}{l}\text { Lucha y proceso frente al PH-Diquís en Térraba. Se saca el ICE del } \\
\text { territorio hasta no hacerse un proceso de consulta formal }\end{array}$ \\
\hline 2010-2017 & Proceso de recuperación continua del territorio de Salitre \\
\hline 2016-2017 & Recuperación del territorio de Cabagra \\
\hline 2014 y 2018 & Recuperaciones en el territorio de Térraba \\
\hline
\end{tabular}

Elaboración propia.

Del mismo modo, se evidencia que la importancia asignada a la autonomía y al territorio de parte de la dirigencia indígena nacional es consecuente, en urgencia, necesidad y poder, con lo que autores académicos que estudian el tema afirman; uno de estos ejemplos es planteado por Berraondo $(2008,19)$ : 
En definitiva, el reconocimiento del derecho al territorio de los pueblos indígenas implica inexorablemente también el reconocimiento de unos derechos políticos de autogobierno o de autodeterminación, que a su vez motivan la trasformación de los modelos de organización política clásicas.

En este conjunto histórico de luchas indígenas en Costa Rica, se aprecia que los 23 años de presión para aprobar PDLDAPI se ha mantenido como un pilar, situación que se torna más evidente cuando se comprende que este proyecto de ley propone la conformación de Consejos Directivos Territoriales, que serán integrados por indígenas, desde donde se administraría y representaría al territorio ante otras instancias sociales, políticos y estatales.

Por otro lado, otro proceso de importante concentración de lucha indígena se relaciona con la oposición al Proyecto Hidroeléctrico del Diquís ( $P$. H. Diquís) que el Instituto Costarricense de Electricidad pretende construir mediante una represa en el río Térraba, afectando directamente a los territorios brunka y térraba ubicados en las cercanías de este río. Con el $\mathrm{P}$. $\mathrm{H}$. Diquís que, de realizarse, el ICE tendría la capacidad de producir $631 \mathrm{MW}$, las y los indígenas opuestos argumentan que también afectaría aproximadamente 1800 ha del área del Humedal Térraba-Sierpe, perjudicando 285 sitios arqueológicos, así como una afectación de 652,24 ha en el territorio de Térraba y 73 ha del territorio de China Kichá (Cole 2009).

Con el P. H. Diquís, las tierras afectadas en Térraba constituyen antiguas zonas indígenas usadas para la agricultura y también utilizadas como medio de navegación para el comercio con otras zonas, como las realizadas actualmente con el pueblo de Ciudad Cortés, ubicado en el cantón de Osa. Sobre esta problemática, Jorge Cole $(2009,12)$ argumenta que:

Muchos de quienes toman decisiones dentro del ICE actualmente son de una corriente política fuertemente capitalista y que facilita la acumulación de la riqueza en una minoría, sin reconocer la misión y mandato fundacional de carácter social que posee el ICE desde su creación. Las políticas macroeconómicas que empezaron a afectar Costa Rica con la entrada de vigencia de los Planes de Ajuste Estructural en la década de los ochentas, más las políticas que impulsan organismos financieros internacionales y ahora el recién aprobado (en Costa Rica) Tratado 
de Libre Comercio entre CA y los Estados Unidos, le han ido quitando poco a poco "el rótulo" y carácter social a esta institución, y han hecho que en su lugar sobresalga el de empresa.

Ante esta forma de intervención en el territorio a gran escala, una buena cantidad de indígenas de Térraba se han organizado de diferentes maneras, aliándose con organizaciones no gubernamentales como el colectivo DITSÖ, con los cuales han realizado capacitaciones sobre proyectos hidroeléctricos. Además, en el año 2005, indígenas de Térraba presentaron un recurso de amparo contra el ICE, ya que dicha institución comenzó la realización de estudios sin haber hecho una consulta previa con este pueblo indígena, sin embargo, este recurso fue declarado "sin lugar" por la Sala Constitucional y en el año 2007, el ICE retomó sus estudios.

Además, según Bohián Pérez Stéfanov (2011), ${ }^{25}$ al interno de Térraba hay una discusión pues hay personas que se mantienen a favor y otras están indecisas, sin embargo, el sector opuesto al proyecto pasó de asesorarse en áreas como patrimonio arqueológico y natural a interesarse por aspectos identitarios y de conservación con el río General, con lo cual el tema del agua fue siendo de mayor de interés, incluyendo reflexiones sobre comunidades no indígenas como Pilas y Bijagual. Que el ICE se mantenga en la zona realizando actividades de intervención se debe a la aprobación que en su momento otorgó la ADI de Térraba, que se debe agregar, ha sido cuestionada por no representar de manera legítima al pueblo indígena Térraba (también llamado bröran), ya que es conocido que dentro de los afiliados y afiliadas a esta ADI se encuentran personas no indígenas. ${ }^{26}$

En el 2006, el Estado y el ICE realizan un acercamiento con indígenas de Térraba para conocer posición sobre el P. H. Diquís, no obstante, este proceso fue cuestionado por la convocatoria empleada y la manera en la que se realizó, razones por las cuales este proceso no fue vinculante, desestimándose (Pérez Stéfanov 2011, 18). De esta manera, el P. H. Diquís se retrasó por la presión de las comunidades que se verían afectadas, tanto en territorios indígenas como fuera de estos. Por este motivo, ante el poco avance de las obras, el gobierno de Óscar Arias Sánchez, bajo el Decreto N. ${ }^{\circ} 34312$ publicado en La Gaceta N. ${ }^{\circ} 31$, del 13 febrero de 2008, el cual declaraba como obra de "conveniencia nacional e interés público" los estudios y obras del Proyecto Hidroeléctrico Diquís, se levantaron varios requisitos al ICE para poder ingresar a las zonas de interés.

Según Angulo (2016), ${ }^{27}$ mediante la sentencia 15711-2016, la Sala IV declaró como inconstitucional el artículo 8, que establece las zonas de Buenos Aires, Chánguena y Cabagra como lugares donde el ICE podía explotar materiales para la represa, instalar máquinas y demás obras incorporadas en esta declaratoria de "conveniencia e interés público" del P. H. Diquís, esto debido al incumplimiento de realizar un "proceso de consulta".
25. Este autor menciona que los pobladores de Térraba cuestionan la falta de información, amenazas, avance de obras sin consulta, deterioro de caminos y la calidad de vida, silencio de autoridades locales, cooptación de líderes comunales, intimidación.

26. Además, Pérez (2011) menciona que hay presencia de un $80 \%$ de personas no indígenas dentro del territorio, lo que se traduce en la tenencia de un $75 \%$ de la tierra en manos de pequeños parceleros y grandes propietarios de ganado.

27.Angulo, Yamileth. 2016. "Sala IV anula permiso dado al ICE para desarrollar Diquís en territorios indígenas".

Elmundo.cr, 2 noviembre. Acceso 3 agosto 2018. https://www.elmundo.cr/sala-iv-a nula-permiso-dado-al-ice-para-de sarrollar-diquis-en-territoriosindigenas/ 
28. EI ICE anunció su retiro de los territorios indígenas el 26 de abril del 2011, un día antes de que el Relator James Anaya finalizara su visita. Boeglin, Nicolás. 2011. "El Diquís y la autonomía de los pueblos indígenas". La Nación, 31 octubre. Consultado el 9 agosto 2018. Acceso: https://www.nacion.com/opinion

29. La iniciativa estatal y el ICE no han abandonado sus intenciones de represar este río y producir energía eléctrica, sin embargo, el no cumplimiento de los procesos de consulta y la alta oposición que hay para con este proyecto, ha hecho que sus acciones tiendan a menos, pero continúen en la agenda gubernamental.

30. El nombre completo es Mesa de Diálogo entre el Gobierno de Costa Rica y los Pueblos Indígenas de los cantones de Buenos Aires y Pérez Zeledón. Además, debe señalarse la participación de las Naciones Unidas y la Defensoría de los Habitantes de Costa Rica, como observadores del proceso. Para conocer otros detalles sobre el conflicto alrededor de este polémico proyecto, visitar: Acción de Inconstitucionalidad contra decreto de conveniencia nacional N. ${ }^{\circ} 34312$ :

Http://koscosambientales.ucr.ac ; y Fernando Jara, Juan. 2018. "Sala IV acoge acción de inconstitucionalidad contra hidroeléctrica Diquís por daño ambiental y patrimonial". La Nación, 14 mayo. Acceso 14 agosto de 2018.

https://www.nacion.com/el-pais
En el 2011, la visita del Relator Especial de Pueblos Indígenas de las Naciones Unidas James Anaya, del 24 al 27 de abril ${ }^{28}$, fue un acontecimiento que marcaría la coyuntura y la presión contra el P. H. Diquís. En el informe de su visita, Anaya llamó la atención sobre la necesidad de la consulta, la cual debió haberse realizado previo a los estudios técnicos, lo cual, señala el Relator, hubiera permitido a las y los indígenas participar en la toma de decisiones y expresar sus deseos e inquietudes con este proyecto. Ante la presencia del Relator de Naciones Unidas, el ICE informó que interrumpiría las operaciones en el territorio de Térraba y abandona la zona (Boeglin 2011).

Con base en este panorama surgido en el contexto de la iniciativa estatal de hacer la represa en el río Grande de Térraba ${ }^{29}$ y las acciones de recuperación de tierras que desde el 2010 han ocupado la agenda de lucha indígena en los territorios de Salitre, Cabagra y Térraba, es que el Estado costarricense ha ido perdiendo legitimidad como garante de los derechos indígenas y sus acciones han sido cuestionadas por parte importante de la dirigencia indígena que está defendiendo sus territorios desde las propias comunidades.

Esta pérdida de poder del Estado llevó a que, en el 2013, el Gobierno -durante la Administración Chinchilla Miranda- propusiera una Mesa de Diálogo $^{30}$ para analizar la agenda política indígena. Este espacio estuvo integrado por representantes del Poder Ejecutivo y representantes indígenas de los territorios indígenas de Salitre, Cabagra, Ujarrás, Térraba, Boruca, Rey Curré y China Kichá que, en reuniones mensuales, discutieron sobre los siguientes puntos:

1. Política pública: Plan nacional de desarrollo y planes de desarrollo de los territorios.

2. Seguridad territorial.

3. Gobernabilidad en los territorios.

4. Ley de Desarrollo Autónomo de los Pueblos Indígenas (Exp. 14 352).

5. Análisis del derecho de consulta a los pueblos indígenas en Buenos Aires y Pérez Zeledón.

El último punto fue incluido por el propio Gobierno con el afán de lograr los medios que lo legitimaran para continuar con el P. H. Diquís, sin embargo, con el cambio de Gobierno en el 2014, la Administración Rivera Solís (20142018) desestimaría este espacio de Mesa de Diálogo y esto llegaría a su fin sin ningún resultado destacable.

Con el final de este espacio de diálogo político, en el 2014, 2015 y 2016, las acciones de recuperación de tierras en Salitre seguirían siendo uno de los escenarios centrales de lucha territorial indígena, dejando en evidencia que las acciones estatales seguían siendo omisas en la resolución de la problemática de la tierra y en el cumplimiento pleno de las garantías territoriales de los pueblos originarios del país. Sin entrar de lleno en la resolución del conflicto de Salitre, el Gobierno costarricense -en la administración Solís Riveradestinó la mayoría de sus esfuerzos en concretar un Mecanismo General de 
Consulta a Pueblos Indígenas, que si bien ayuda en la relación Estado y Pueblos Indígenas, no atendió las demandas de varios territorios indígenas respecto aspectos territoriales y de gobernabilidad ${ }^{31}$.

\section{Reflexiones finales. Autonomía y territorio indígena en disputa}

En este artículo, se mostró que uno de los temas centrales en la agenda política de los pueblos indígenas es el control del territorio, se constató sobre la poca e incompleta acción estatal en varios momentos y ante diferentes demandas concretas planteadas por pueblos indígenas del país. Se puntualizó sobre el poco interés del poder legislativo en la aprobación de un proyecto de ley que aun siendo propuesto desde la misma dirigencia indígena hacia mayor control de sus tierras y territorios, lleva más de dos décadas en un tenue o inexistente avance.

Hay evidencia de una continua acción de los pueblos indígenas enmarcados en la lógica de mantener control sobre sus territorios y avanzar en la posibilidad de ampliar derechos como pueblos, sus demandas y propuestas señalan un cambio necesario en las relaciones de control estatal en relación con la autonomía política que el Estado ha construido como forma homogénea de intervenir el país, la lógica de homologar las Asociaciones de Desarrollo en territorios indígenas con directrices generales desde DINADECO se muestra como un modelo caduco; hecho ignorado por las diferentes instancias y administraciones estatales que hacen caso omiso de este reclamo indígena.

Si bien el proceso documentado apunta a una secuencia de luchas indígenas desde la década de 1970, las acciones de recuperación de tierras y la consigna de luchar "desde los territorios", desde el año 2010, han colocado nuevos escenarios de disputa en los que la autoridad estatal tiende a menos y sigue siendo cuestionada por los pueblos indígenas que demandas tierra y autonomía.

Es necesario entender este nuevo ciclo de luchas indígenas como síntomas de cambio y de desgaste de las relaciones estatales con estos pueblos que muestran menores canales de comunicación, sin avecinarse -por el momento- respuestas satisfactorias por parte del Estado en relación con estos pueblos y territorios. La urgencia de cambios en las versiones que las diferentes instancias del Estado mantienen sobre los pueblos indígenas debe ser abandonadas dando paso a expresiones institucionales en las que se entienda que el poder estatal no es capaz de intervenir satisfactoriamente las demandas y necesidades de estas poblaciones y, por ende, las figuras de autodeterminación de estos pueblos deben plantearse con urgencia, siendo este el camino para interpelar a reales modelos de sociedad pluriculturales y a un abandono del Estado colonialista que se percibe como única instancia depositaria del poder social, cultural y político. Hay clara evidencia de que la centralidad del poder en instancias estatales ha fracasado y continuar con esa
31. Para conocer el proceso de construcción de este mecanismo, sus etapas, contenidos y el resultado mismo de este mecanismo, visitar http://www.consultaindigena.go. $\mathrm{cr} /$ 
lógica solo agudiza las injusticias ampliamente denunciadas por los pueblos indígenas.

Finalmente, como se ha explicado, la presión sobre los territorios y pueblos indígenas se ha dado desde la colonización, la posterior fundación del Estado, su desarrollo en el siglo XX y en el presente modelo neoliberal en el siglo $\mathrm{XXI}$; donde el incumplimiento de derechos y la desposesión de tierras indígenas, como continuidad de la violación de derechos humanos de estos pueblos, son las motivaciones para la conformación de luchas, demandas y propuestas de dirigencias indígenas tendientes a un mayor control político de sus territorios desde la autodeterminación de su autonomía como pueblos.

\section{Bibliografía}

Arias Chaves, Sugey, Priscila Barrios Alfaro, Heiddys García Brenes, Sebastián Martínez Arias y César Moya Aburto. 2016. Desafíos de la autonomía indígena en Costa Rica. Tesis para optar por el grado de Licenciatura en Antropología Social. Universidad de Costa Rica.

Barrantes, Claudio. 1985. Los caminos de Pablo Presbere en la Época Colonial y los caminos de Pablo Presbere en 1983. San José, Comisión Nacional de Nomenclatura, 1985.

Bello, Álvaro. 2004. Etnicidad y ciudadanía en América Latina. La acción colectiva de los pueblos indígenas. Chile: CEPAL.

Blanco Acosta, Denia; Oldemar Pérez Hernández, Sofía Solano Acuña y Adriana Torres Ortiz. 2009. "Proyecto de Desarrollo Autónomo de los Pueblos Indígenas en Costa Rica: proceso y limitaciones". En La gobernabilidad de los pueblos indígenas en Centroamérica desde la perspectiva comunitaria, editado por Xinia Zúñiga Muñoz, 42-72. San José, Costa Rica: UNED.

Bermúdez, Luisa (2018, 31 marzo). "Costa Rica: Pueblos ancestrales de Térraba recuperan sus tierras". Segundo enfoque. http://segundoenfoque.com/costa-rica-pueblos-ancestrales-de-terrabarecuperan-sus-tierras-2018-03-31. Acceso 28 marzo 2018.

Berraondo López, Mikel. 2008. Entre los reconocimientos de papel y la garantía de un derecho. Territorios Indígenas. Programa para la implementación de los pueblos indígenas.

Boaventura dos Santos. 2010. Descolonizar el saber, reinventar el poder. Consultado el $14 \quad 2018$. http://www.boaventuradesousasantos.pt/media/Descolonizar\%20el \%20saber_final\%20-\%20C\%C3\%B3pia.pdf 
Brenes, Greivin (1998, 13 octubre). “Aborígenes reclaman sus tierras”. La República, 6A.

Carls, Jürgen (2013). Desarrollo de las reservas indígenas en el sur de Costa Rica. San José: Editorial Universidad para la Paz.

Chacón, Rubén; Guevara Berger, Marcos. 1992. Territorios indios en Costa Rica: orígenes, situación actual y perspectivas. García Hermanos S. A.

Chacón, Rubén. 2001. Guía legal para los Pueblos Indígenas de la Región Brunca. San José: Impresora Gossestra Intl. S. A.

Chavarría Sancho, Dennise; Víctor García Barrenechea, Rebeca Gu Navarro, Andrés López Arias. 2013. Pueblos y Acciones Políticas en Costa Rica: Los Conflictos de la Agenda (2002-2010). Memoria de Seminario para optar al grado de Licenciatura en Ciencias Políticas. Universidad de Costa Rica.

Cole Villalobos, Jorge. 2009. Pueblos indígenas afectados por desarrollos mineros, petroleros y represas en Mesoamérica, el caso de Costa Rica. Informe de Consultoría UICN. Consultado 10 agosto 2018. http://pueblosindigenas.odd.ucr.ac.cr/images/documentos/pdf/Pueblos \%20indigenas \%20y\%20megaproyectos.pdf

Diario Digital Nuestro País. (2017, 27 de enero). "Gobierno de Costa Rica firma acuerdo con indígenas para cumplir orden de CIDH".

El Periódico CR. 2012. "Indígenas confieren a la Asamblea cédula de la desvergüenza". El Periodicocr.com, http://elperiodicocr.com/indigenasconfieren-a-la-asamblea-qcedula-de-la-desvergueenzaq/. Consultado 28 marzo 2018.

Gabriel, Leo y López y Rivas, Gilberto. 2005. Autonomías indígenas en América Latina. Nuevas formas de convivencia política. México: Plaza y Valdés.

Guerrero, Angie (2016, 19 abril). "Gobierno responde críticas por conflictos con indígenas". Diario Digital CrHoy. http://www.crhoy.com/archivo/gobierno-responde-a-criticas-porconflictos-con-indigenas/nacionales/.

Guevara Víquez, Federico. 2009. "Impactos sociales y culturales del Proyecto Hidroeléctrico Diquís hacia los pueblos indígenas de Buenos Aires". Cuadernos de Antropología. 19: 167-181. Acceso el 25 marzo 2018. https://revistas.ucr.ac.cr/index.php/antropologia/article/view/6880

Guevara Víquez, Federico. 2011. Cronología básica de los pueblos indígenas de Costa Rica. Desde los inicios del siglo XVI hasta el año 2000. Siwá Pákö, Costa Rica. Consultado 5 de agosto 2018. http://www.ciderural.una.ac.cr/attachments/article/61/LIBRO_Cronologia\%20Basica \%20de\%20los\%20Pueblos\%20In.pdf

Ibarra, Eugenia. 1990. Las sociedades cacicales de Costa Siglo XVI. Editorial Universidad de Costa Rica. 
Marín Hernández, Juan, Jorge Bartels y Oriester Abarca. 2011. El Sur-Sur. Trayectorias y perspectivas de una región en proceso de formación: 1821-2010. San José: Editorial Alquimia.

Mires, Fernando. 1991. El Discurso de la Indianidad la cuestión indígena en América Latina. Editorial Departamento Ecuménico de Investigación. Costa Rica.

Oreamuno, Gustavo (2016, 30 setiembre). "Recuperan finca en Brazo de Oro, en el territorio indígena de Iriria Bribri Sa Ka (Cabagra)". http://www.vocesnuestras.org/2016-09-30/articulo/recuperan-fincabrazo-oro-territorio-indigena-iriria-bribri-sa-ka-cabagra

Bohián Pérez, Stéfanov. 2011. "Reflexiones sobre el proyecto Hidroeléctrico El Diquís sus impactos sociales en las comunidades de Térraba, Buenos Aires y Ceibo". Revista Reflexiones 90(2) 9-25. Acceso 10 agosto de 2018. https://revistas.ucr.ac.cr/index.php/reflexiones/article/view/14493

Quesada García, David. 2017. "Sistematización de experiencias: Reconstrucción de la memoria histórica del Frente Nacional de Pueblos Indígenas (FRENAPI), dilucidando las experiencias de contraste y las acciones contenciosas en procura de construcción de derechos humanos". Revista Latinoamericana de Derechos Humanos, volumen 28 (1), 117-146, I semestre 2017 (EISSN: 2215-4221).

Rivera, Ernesto (1999, 6 octubre). "Indígenas marchan por promesas". La República, 4A.

Salas Díaz, Uri. 2016. Las inundaciones y el Siwâ. Acercamiento a la historia ambiental de Talamanca. EUNED, Costa Rica.

Sancho, Manuel (2013, 17 de enero). "Familias indígenas recuperan tierras en la Zona Sur". CrHoy. http://www.crhoy.com/archivo/familiasindigenas-recuperan-tierras-en-la-zona-sur/nacionales/. Consultado 26 de marzo 2018.

Solórzano, Juan Carlos. 2011. "La resistencia de los pueblos indígenas en el siglo XX y la actualidad". Conferencia preparada para presentar en ARADIKES: Asociación Aborigen del Dikes, Buenos Aires de Puntarenas, Costa Rica, 26 de marzo de 2011, para el Programa de gestión local de la UNED.

Zúñiga Muñoz, Xinia; Juan Gutiérrez Sloan, Pablo Sibar Sibar, Luisa Bejarano Montezuma, Javier Montezuma Montezuma y Guillermo García Segura. 2014. La lucha por la cedulación del pueblo ngäbe en Costa Rica: alcances y significados político-culturales en la década del noventa. Informe de Investigación del Centro de Investigaciones en Cultura y Desarrollo de la Universidad Estatal a Distancia de Costa Rica. https://investiga.uned.ac.cr/cicde/images/ngobe.pdf 